\title{
Child birth in the exam centres in Nepal: An overlooked Public Health issue!
}

\author{
Pramod R Regmi ${ }^{1-2}$, Nirmal Aryal ${ }^{3}$, Edwin van Teijlingen ${ }^{4-6}$ \\ ${ }^{1}$ Faculty of Health and Social Sciences, Bournemouth University, UK ${ }^{2}$ Chitwan Medical College, Tribhuvan University, Nepal ${ }^{3}$ Department of Medicine, University \\ of Otago, New Zealand ${ }^{4}$ Centre for Midwifery, Maternal and Perinatal Health, Faculty of Health and Social Sciences, Bournemouth University, UK ${ }^{5}$ Manmohan \\ Memorial Institute of Health Sciences, Tribhuvan University, Nepal ${ }^{6}$ Nobel College, Pokhara University, Nepal
}

Received:

5 April 2016

Revised:

6 April 2016

Accepted:

6 April 2016

\section{${ }^{\star}$ Correspondence: pregmi@bournemouth.ac.uk Faculty of Health and Social Sciences, Bournemouth University, England, UK}

For many years, there have been news almost every year in the mass media in Nepal on school leaving certificate (SLC) exam attendees giving birth in the exam hall. This year too, we are attracted by a news entitled 'SLC attendant gives birth to baby girl'. This occurred during the SLC examination at one of the exam centres located in Jajarkot (1), a rural district in mid-western region of the country. Another examinee of the SLC exam this year had also given birth to a baby on the eve of beginning of this year's SLC exam. This signals us that childbirth or emergency health care needs in Nepal is not always limited at health care premises.

We are not surprised to read about childbirth during the exam as it is not a new phenomenon. In contrast, these circumstances are very rare in the developed countries. In countries like the UK, all sorts of arrangements are made to ensure the pregnant student is in no way disadvantaged in her studies because of her pregnancy. This may involve being given a year out to return after the baby has been born and given time off during studies to attend antenatal classes and so on. Last year, a news went viral when a pregnant student in the USA had successfully completed her exam in hospital bed while giving a birth (2). There was another incident in Bihar, India where a student during her 12th grade exam was rushed to a hospital (3). However, childbearing during exam in the Nepal is different. These are often observed in rural areas where early marriage is a norm and provision of basic health care facilities including delivery care is not widely available. For example, only $36 \%$ of birth in Nepal take place with the assistance of a skilled birth attendant (SBA) and the situation in rural areas is even worse (4). Around two-thirds of women in rural areas in Nepal generally deliver their babies at home alone or with the help of female relatives or traditional midwives (4).

The recent birth in an exam centre (school) -which fortunately had no adverse outcome- was supported by the female teachers of the schools. We agree that it is not always possible to receive basic health care in the rural areas when such incidents occur in non-health care settings. Moreover, it is difficult transferring the service users to the nearest health facilities due to the poor road networks if an emergency care (e.g. if complex intervention) is required. We thus like to stress the need to initiate discussion how such situation can be better served by health care professionals. We have a notion that these young 'examinee mother' may face 'double' challenge - as being an examinee and going into a labour during examination.

SLC exam in Nepal is usually considered as the "iron gate" and the pass percentage is below $50 \%$. Failure in the SLC exam often invites adverse outcomes from the family and the society. This calls for legislation to allow pregnant examinees to re-sit the exam as a first sitting. However, the school and examination system in Nepal is too rigid and competitive. For example, there is another annual phenomenon of suicide or suicide attempts by SLC failed students. Additionally, after the childbearing, women in the many rural areas of western regions of the country are segregated from their families and are sheltered in a temporary hut, leaving them with fewer opportunities to prepare remaining exams or to look after their child at the highest standard.

Nepal is one of just a few countries in the world which has made significant progress in terms of maternal and child health (5). However, use of modern family planning method is still very low for currently married adolescents and young people (e.g. contraceptive prevalence rate is $14.4 \%$ for $15-19$ age groups and $23.8 \%$ for 20-24 age groups) (4), posing them more vulnerable for unwanted pregnancies. The new constitution (2015) of Nepal enshrined the several rights around Sexual and Reproductive Health (SRH) and interestingly pregnant women are included as one of the vulnerable groups among many other socially disadvantaged groups such as Lesbian, Gay, Bisexual and Transgender (LGBT).

We have three major recommendations to deal with this issue. First, local health care providers can prepare a list of expectant mothers during the month of exam and ready themselves for any birth circumstances at the exam centres. Secondly, new mothers should be provided with another exam date sooner rather than having to wait for next year's exam period. Finally, and a bit more long term we should ensure the delivery of effective sex education which can empower adolescents to prepare them for planned pregnancy and better motherhood. We should also try to make contraceptives easily available to adolescents to ensure that fewer pregnancies occur in school going adolescents. The Ministries of Education and Health \& Population 
should work together to address this issue. Together, we can ensure a safe delivery, health and wellbeing of examinee mother.

\section{Competing interests}

The authors declare that they have no competing interests.

\section{Funding}

No funding received

\section{References}

1. The Himalayan Times. Girl gives birth during SLC exam in Jajarkot. Available from: https://thehimalayantimes.com/nepal/girl-gives-birth-slc-exam-jajarkot/ (Accessed 3 April 2016)

2. The Huffington Post. Determined New Mom Finishes Psychology Exam While In Labor. Available from: http://www.huffingtonpost.com/entry/determined-newmom-finishes-psychology-exam-while-in-labor_us_564b4c51e4b08cda348a92dc (Accessed 3 April 2016)

3. Daily Bhaskar. Class 12th girl gives birth to a child inside the examination hall. Available from: http://daily.bhaskar.com/news/BIH-class-12th-girl-gives-birth-toa-child-inside-the-examination-hall-4528819-NOR.html (Accessed 3 April 2016)

4. Ministry of Health and Population, New ERA, ICF International Inc. Nepal Demographic and Health Survey 2011. Kathmandu: Ministry of Health and Population, New ERA, and ICF International, Calverton, Maryland.2012.

5. Regmi P, Van Teijlingen E, Hundley V, Simkhada P, Sharma S, Mahato PK. Sustainable Development Goals: relevance to maternal and child health in Nepal. Health Prospect: Journal of Public Health. 2016 Feb 26;15(1):9-10. 